\title{
Para una Bibliografía de Marco Denevi
}

$\mathbf{M}_{\text {comentaristas de la literatura hispanoamericana contemporánea. }}^{\text {arco Denevi es uno de los escritores argentinos más citados por los }}$ Desde I955, año en que obtuvo el prestigioso Premio Kraft su primera obra de ficción, Rosaura a las diez, ha sido Denevi una de las figuras más interesantes de toda América Latina en el campo de la literatura de imaginación y fantasía. El gran narrador de Rosaura se disfrazó después de satírico, y luego de moralizador, cultivando siempre un tono abstracto, irónico $y$, a veces, casi cínico.

Dice Denevi que dentro de poco, tal vez en el 67, terminará y retocará por última vez su segunda novela que ha de llamarse Los viajeros del cielo y de la tierra. Mientras tanto, anda leyendo sus "Falsificaciones" (ver bibliografía) por Radio Nacional de Buenos Aires y sigue como asesor letrado de la Caja Nacional de Ahorro Postal, cargo que desempeña desde años antes de la mañana del 55 cuando amaneció "escritor". Un caso bastante raro el de Denevi. Declaró entonces: "Rosaura es mi primer libro; su primer párrafo, mi primer párrafo; la palabra con que comienza, mi estreno como (¿cómo decirlo?), como ejercitador de las letras'."

Aquí, pues, sigue la bibliografía de Marco Denevi, completa hasta diciembre de 1966 . 


\section{Bibliografía de Marco Denevi}

I. Rosaura a las Diez. Novela. Premio Kraft I955. Faja de Honor de la Sociedad Argentina de Escritores, I955.

A) Ediciones en castellano:

I. Guillermo Kraft Ltda., Buenos Aires, primera edición I955; octava edición I960.

2. Columba, Buenos Aires, I958. Versión condensada, con ilustraciones.

3. Charles Scribner's Sons, New York, I964. Texto abreviado. Con introducción, notas y vocabulario español-inglés por Donald Yates.

4. Contenido, No I7. México, D. F., r964. Texto condensado.

B) Edición en inglés:

5. Rosa at 'Ten O'clock. Traducción de Donald Yates. Holt Rinehart \& Winston, New York, I964.

C) Edición en alemán:

6. Rosaura Kam Um ZehN. Traducción de Curt Meyer-Clason. Kiepenheuer \& 'Witsch, Colonia-Berlín, r96r.

D) Versión cinematográfica.

7. Guión de Marco Denevi y Mario Soffici, I957. La película fue estrenada el 6 de marzo de I958. Primer premio del Instituto Cinematográfico Argentino. Premio de la crítica a la mejor adaptación.

E) Versión teatral.

8. Pieza en tres actos, por Marco Denevi. Estrenada en Buenos Aires el I2 de mayo de I96r.

F) Versión para televisión.

9. Guión de Marco Denevi y Jacobo Langsner. Transmitida por Canal 9, de Buenos Aires, noviembre-diciembre, I96I. 
II. Ceremonia Secreta. Novela corta. Premio Internacional "Life en Español", I960.

A) Ediciones en castellano:

Io. Life en Español, números del I 2 y 26 de diciembre de x960.

ix. Ceremonia Secreta y Otros Cuentos de América laTINA. Doubleday \& Company, New York, I.96I. Incluye todos los cuentos premiados en el concurso de "Life en Español".

i2. Ceremonia Secreta y Otros Cuentos de Marco DeNEVI. The Macmillan Company, New York, 1965. Con introducción, notas y vocabulario español-inglés por Donald Yates. Incluye, además de C. S., los siguientes cuentos: "El emperador de la China", "El Maestro traicionado", "Génesis", "Dulcinea del Toboso", "Apocalipsis", "La cola del perro", "La mariposa" y "Fábula".

B) Ediciones en inglés;

13. Secret Ceremony. Traducción de Harriet de Onís. TimeLife Inc., New York, r96r. (Edición privada).

14. Prize Stories From Latin América. Doubleday \& Company, New York, 1963. Comprende todos los cuentos premiados en el concurso de "Life en Español". La traducción de C. S. es la misma que se cita anteriormente

C) Otras traducciones:

I5. Cermemonia Secreta. Traducción al italiano por Ada Cianciolo. Inédita.

D) Versión para televisión.

r6. Guión de Marco Denevi. Transmitida por Canal 9, de Buenos Aires, julio-agosto, 1961. Premio "Martín Fierro".

III. Los EXPEDIEnTtes. Pieza teatral en tres actos. Estrenada el 20 de septiembre de 1957. Premio Nacional de Teatro (género comedia).

I7. Edición en castellano: Talía, Buenos Aires, 1957. 
IV. El Emperadior de ta China. Pieza teatral en un acto. Estrenada el $\mathrm{r}^{\circ}$ de diciembre de 1960.

18. Edición en castellano: Ediciones Aguaviva, Buenos Aires, I960. Con ilustraciones de Benicio Núñez.

V. Antología Imaginaria. Serie de textos apócrifos (cuentos, apólogos, fábulas, poesía, etc.).

Publicada parcialmente en la revista Cuadernos, París, números 75 (agosto, I963) y 8 I (febrero, I964).

\section{Comprende:}

I9. (No 75) : "Historia del emperador Wu Ti y su primer ministro Wang Mang", "La verdad sobre Paolo y Francesca", "El Maestro traicionado", "Un fanático de la etiqueta", "Fábula de la hormiga", "Un precursor de Cervantes", "Variación sobre Lázaro", "El mensajero mendaz", "Un hombre calumniado", "La anunciación al traidor".

20. (No 8I) : "La caída de los héroes, I", "The Female Animal", "No le cortéis la cola al pavo real", "Versión bárbara de Tristán e Isolda", "Alegoría de los destinos y los honores", "E1 público siempre pide más", "Orden de matar en Bizancio", "La caída de los héroes, II", "La poesía", "La cicatriz", "Las sombras".

21. La segunda serie de las dos mencionadas precedentemente fue reproducida en la revista Prensa Literaria, números 4 y 5 , San Juan de Puerto Rico, agosto-septiembre, I964.

\section{ADDENDA:}

22. "The Female Animal", figura, además, en la antología Crónicas del amor, selección y prólogo de Julia Constenla. Julio Alvarez, Buenos Aires, I965.

23. "Historia del emperador Wu Ti y su primer ministro Wang Mang" (con el título de "El emperador de la China") más las fábulas "Boroboboo" y "La cola del perro" en Novelistas contemporáneos bispanodmericanos, selección, prólogo y notas por Fernando Alegría. D. C. Heath, Boston, USA, I964. 
24. "La poesía", (de la Antología imaginaria), con el título de "La cigarra en el hormiguero", y "No le cortéis la cola al pavo real", más la fábula "Fragmentos de un diario intimo," en Américas, revista de la Unión Panamericana, Washington, D. C. Edición en español: junio, 1964; en inglés: May, 1964; en portugués: junho, I964.

\section{Cueintos no Mencionados Precedentemente.}

25. "Memorias de Margarita", en Cuentos de crimen y misterio, selección y estudio preliminar por Juan Jacobo Bajarlia. Julio Alvarez, Buenos Aires, r964.

26. "Los anteojos", en la revista El Hogar, Buenos Aires, 28 de septiembre de 1956. Premio de la Dirección General de Cultura.

27. "El nacimiento de Dulcinea", en el suplemento literario del diario La Nación, Buenos Aires, 4 de noviembre de 1956.

28. "Otra versión de Edipo", idem, i2 de enero de r958.

29. "Variación sobre Lázaro" (otra versión del cuento aparecido en Antologia imaginaria, v.) en la revista El Hogar, 27 de abril de 1956 .

30. "La mosca", en el suplemento literario del diario La Mañana, de Mar del Plata, Argentina, 28 de marzo de I96r.

3I. "Yayá", en el suplemento literario del diario Correo de la Tarde, 29 de agosto de $196_{3}$, y en la revista Autoclub, Buenos Aires, agosto, Ig64.

VII. EL GRAN KlHaN. Pieza teatral en un acto. Es la primera versión de "El emperador de la China".

32. El Hogar, 30 de noviembre de 1956 . (Los textos son completamente diferentes).

VIII. Tres Esquicios para Televisión:

33. La desconocida del sábado, Orfeo y La Fiesta. Estrenados por Canal 7, de Buenos Aires, 1957.

Nota: Orfeo, en versión teatral, se estrenó el $I^{\circ}$ de diciembre de $x 960$ y aparece publicado en su versión original para TV en la revista $\mathrm{El} \mathrm{Hogar,} 7$ de febreró de ${ }_{995} 8$. 
IX. Cartas a un Escritor que no iEscribe.

34. № 22 (mayo-junio de 1963 ), Bibliograma (órgano del Instituto Amigos del Libro Argentino), Buenos Aires.

35. Idem., № 27 (julio-agosto de 1964).

36. "Respuesta a Silvina Bullrich", ídem, número 28 (septiembre octubre de I964).

X. Falsificaciones. Serie de textos apócrifos (cuentos, apólogos, fá. bulas, etc.).

37. Edición en castellano: EudebA, Buenos Aires, I966. Recoge los textos de Nos. I9 y 20, en forma revisada, más 63 textos nuevos.

XI. Un Pequeño Café. Novela.

38. Edición en castellano: Editorial Calatayud, Buenos Aires, 1966.

Donald A. Yates

Michigan State University 